\title{
How a Convergence Product Affects Related Markets: The Case of the Mobile Phone
}

$\overline{\text { Misuk Lee, Jongsu Lee, and Youngsang Cho }}$

Analyzing the diffusion of a convergence product is a new and challenging research field. It is very difficult to find research dealing with this issue due to the inherent complexity and lack of data. In analyzing the diffusion of a convergence product, we should simultaneously take into account its relationship with related single-function products because of their similarities in terms of technology and functionality. In this study, we empirically analyze the diffusion of the convergence mobile phones in South Korea and find that the convergence products can affect the diffusion of MP3 players and digital cameras positively or negatively. This research may be significant for business strategies in technology management and product development.

Keywords: Convergence product, diffusion, mobile phone, digital camera, MP3 player.

Manuscript received Oct. 3, 2008; revised Dec. 16, 2008; accepted Dec. 23, 2008.

Misuk Lee (phone: + 822880 2541, email: misuk99@snu.ac.kr) and Jongsu Lee (email: jxlee@snu.ac.kr) are with the Department of Technology Management, Economics and Policy Program, Seoul National University, Seoul, Rep. of Korea.

Youngsang Cho (phone: + 8255320 3878, email: cho.youngsang@gmail.com) was with the Department of Technology Management, Economics and Policy Program, Seoul National University, Seoul, Rep. of Korea and is with the School of Management, Inje University, Gimhae, Rep. of Korea.

\section{Introduction}

Convergence is a pervasive concept and its definitions are diverse. In this paper, we adopt the concept in [1], where device convergence means that many kinds of existing devices are incorporated into a new converged device which enables consumers to use converged services. From the perspective of markets and consumers, technology convergence is important because of the diversification of value through increased services. From the viewpoint of firms that produce and sell these products, the introduction of a convergence product is an important business strategy that can offer advantages such as product differentiation, risk diversification, market extension, and so on. Firms also can manage their new product development process and new product launches with technological convergence [2], [3].

However, the successful marketing of a convergence product is often difficult in reality. Despite a firm's best efforts, consumer response to a new convergence product is not always positive, which leads to its failure. Furthermore, the boundaries of traditional industries may become vague, in that convergence takes place in the intersection of change between technologies, products, and industries [4]. Because of market uncertainty surrounding high-tech convergence products, performing diffusion analysis and demand forecasts is all the more necessary.

Studying the diffusion of a new convergence product is different from studying the diffusion of a traditional singlefunction product. The diffusion of a new convergence product is, by its very nature, always related to the diffusion of singlefunction products whose function has been merged into the convergence product because the convergence product can substitute or complement the single-function products. For 
example, the market potential of a single-function product facing market maturity can be extended by a new convergence product, while another single-function product in the early stages of the market may lose its customers to the convergence products. In addition, because a new convergence product has many of the same attributes as its related single-function products, we can gather useful information for demand forecasting for a new product from the diffusion patterns of existing single-function devices.

The purpose of this research is to suggest the diffusion pattern of a convergence product and address how a convergence product affects the markets of related singlefunction products. In particular, we empirically analyze the diffusion of the convergence mobile phones in the South Korean market and also attempt to explain how the diffusion of convergence mobile phones affects the diffusion of their related single-function devices, such as digital cameras and MP3 ${ }^{1)}$ players.

The mobile phone is a successful convergence product; however, to date, there has been no research analyzing the diffusion of these mobile phones in terms of convergence products. This may be due to the insufficiency of market data and the absence of an established approach for studying the diffusion of convergence products. We combine existing diffusion models fitted to the market structure of convergence mobile phones and empirically analyze the relationships among the markets of the convergence products and their related single-function products.

The remainder of this research is organized into several sections. In the next section, we examine the status of the mobile phone marketplace in South Korea. We then review the relevant literature and set out our research model. The data and empirical analysis results are presented, and finally, we offer some managerial implications and a conclusion.

\section{Status of the Mobile Phone Market in South Korea}

For some years to come, the worldwide mobile phone market will be characterized as having a two-part trend: (i) strong growth in subscribers in new markets, such as the Asia-Pacific, Eastern Europe, and Africa, and (ii) continued replacement demand in mature markets, such as Western Europe and the United States [5]. Some markets, such as those of South Korea and the United States, have already reached maturity in terms of new subscriptions and have entered a replacement phase. Figure 1 shows the cumulative number of subscribers to South Korean mobile telecommunications services over the past 15 years. In the 1990s, the total number

1) Motion Picture Experts Group (MPEG) Audio Layer 3.

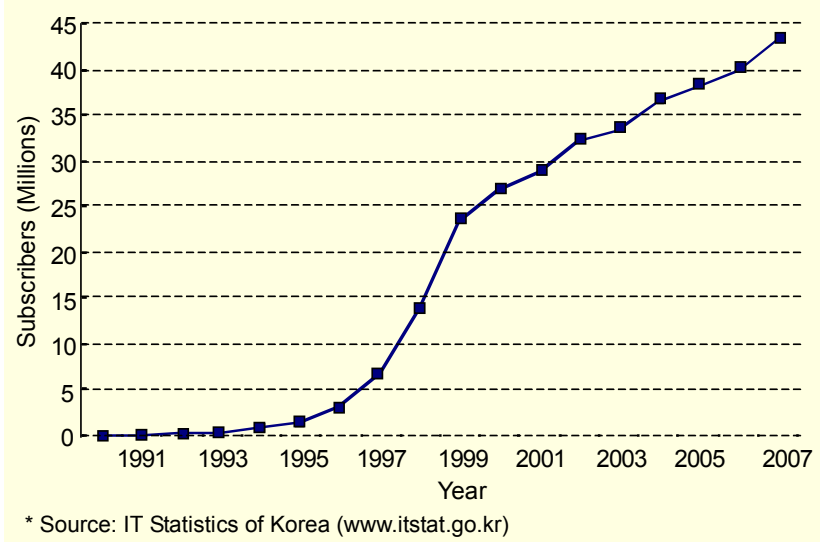

Fig. 1. Cumulative subscribers of mobile communications services in South Korea.

of subscribers grew annually at rates of $90 \%$ to $100 \%$; after 2000 , however, the growth rate slowed to just $4 \%$ to $5 \%$. This means that for companies selling mobile phones, replacement purchases are now more important than first purchases in the South Korean mobile phone market.

These days, many functions, such as the ability to take pictures, play music, and facilitate banking, have been converged into mobile phones. In accordance with these trends, the criteria that a consumer uses to choose a mobile phone have expanded beyond the original function of making a phone call to include additional attributes, such as slimness of design, provision of digital content, and other convergence functions. These multifunctional mobile phones have the great potential to drive replacement purchases of mobile phones and broaden the South Korean mobile market.

In particular, the camera phone is considered a successful digital convergence product that merges the functions of the mobile phone and the digital camera, and it has already established a solid market foundation. Initially, the camera attributes embedded in camera phones were inferior to those found in the original digital cameras; however, with the continuous improvement of camera phone attributes, the camera phone is nowadays considered a threat to the digital camera market. Among digital camera attributes, resolution (or sensor elements), which is usually represented by the number of pixels offered by the camera, is a salient factor. Therefore, the ratio of camera phone pixels to digital camera pixels is a measure not only of the attributes of the camera phone but also of the relative level of technological convergence. As Fig. 2 shows, the ratio of the average number of pixels offered in a camera phone to the average number of pixels offered in a digital camera has been increasing year by year in South Korea.

The MP3 mobile phone can also be regarded, along with the camera phone, as both a driving force for mobile phone market growth and a bridge product in bringing about the realization of 


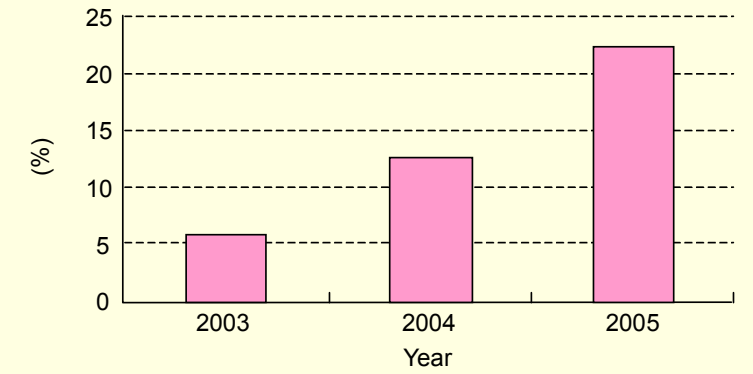

Fig. 2. Ratio of average pixels in a camera phone to average pixels in a digital camera.

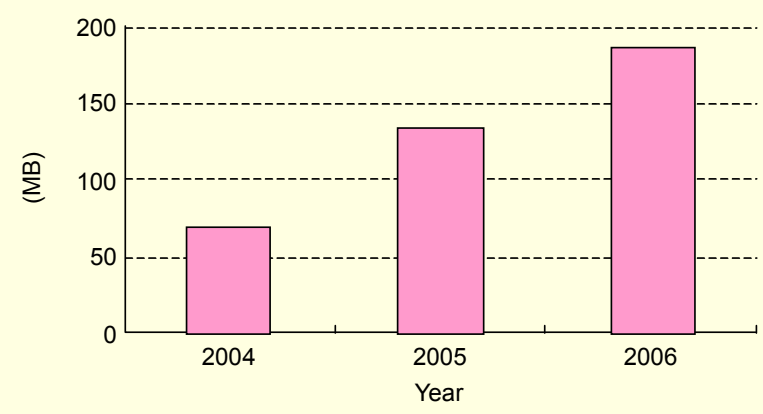

Fig. 3. Average memory capacity of MP3 mobile phones in South Korean market.

a mobile TV phone in the near future. In early models, MP3 mobile phones had only a basic music-playing functionality; nowadays, however, continuous improvements to the technology make them viable substitutes for any MP3 player in terms of functionality and memory capacity. Among the various attributes of the MP3 mobile phone, memory capacity is of paramount importance. Mobile phones contain two types of memory: SDRAM for basic software and NAND flash memory for data such as music and photos. Consumers need sufficient memory capacity if they are to use MP3 mobile phones as they would traditional portable MP3 players, and product suppliers have been quick to fulfill this consumer demand. Figure 3 shows that the average memory capacity of MP3 mobile phones in South Korea has increased every year since 2004.

The provision of digital content to mobile phone users is becoming an ever-increasing priority, and firms with global reach are scrambling to compete in the MP3 mobile phone market by intensifying their phones' music functions and related content services. Nokia began providing music content in 2007 through its download catalogue, Loudeye, and Sony Ericsson has plans to launch its online music space, M-BUZZ. Apple, the leader in the MP3 player market, introduced the iPhone in 2007 and began selling it in North America, Europe, and Asia. Samsung Electronics also has developed marketing strategies for MP3 mobile phone products, focusing on their firm's strengths in the mobile phone and semiconductor markets. On the other hand, in South Korea's mobile phone market, three mobile telecommunications service providersSK Telecom, KTF, and LG Telecom-offer unique online music services through their respective Internet portals: Melon, Dosirak, and Musicon. This shows that the digital content business, such as that exemplified by an online music service, affords mobile telecommunications providers the opportunity to earn additional profits.

\section{Related Literature}

Though a number of academic studies have focused on convergence products, there have been no studies of the relationship between a convergence product and its related single-function products from the viewpoint of diffusion. Therefore, it may be meaningful to review diffusion studies that reflect multiple facets of convergence products.

As mentioned above, a convergence product has a relationship with its related single-function products; existing products that were once used independently can either become substitutes for each other because of the unification of their functions [6] or become complementary from a user perspective. In [7], to consider this type of interrelation between products, a multiproduct diffusion model is proposed which assumes that the diffusion of the $i$-th product will affect the diffusion speed of the $j$-th product. The multiproduct diffusion model has been used for diffusion analysis of successive generation products [8]-[10].

For our empirical analysis of the convergence phone, we need to consider the characteristics of the existing products and markets. Though the Bass model [11] is widely used because of its excellent fit and forecasting, it is inappropriate for examining diffusion in a mature market, where first purchases are all but finished and replacement purchases are the main consideration [12]. The mobile phone market in South Korea is a mature one in terms of first purchases; therefore, it is more appropriate to use a replacement purchase diffusion model to analyze it. In [13]-[15], repeat purchase diffusion models are presented which consider consumers' replacement purchase behavior.

In the case of the mobile phone market, replacement purchases can easily be separated from first purchases because new subscriptions to mobile telecommunications services constitute consumers' first purchases. South Korea is an advanced market for the mobile telecommunications industry, so there have been many studies on the topic. For example, in [16], a choice-based model is used to forecast the diffusion of telecommunications service subscribers in the South Korean market. In [17], a new replacement-purchase diffusion model is 
developed at the brand level and the South Korean mobile terminal market is empirically analyzed.

Despite the interest in the mobile phone market, the relationship between a convergence mobile phone and its related single-function products has been neglected in diffusion studies. For example, as mobile phones and digital cameras are considered two different products, no diffusion studies have treated the mobile phone as a product in competition with the digital camera. In another area, most of the literature dealing with the online music market focuses on illegal MP3 filesharing, free downloading, and copyright issues [18]-[21]. On the subject of diffusion, in [22], a new diffusion model is derived which considers the relationship between software and hardware as well as the impact of software piracy. In [23], software piracy is also addressed by a diffusion model and a model for the piracy protection levels of firms is derived. However, these works are not directly applicable to convergence products.

We have set our model using existing diffusion models. First, we use the replacement-purchase model of [17] to analyze the South Korean mobile phone market, considering some of the attributes of the convergence mobile phone, and analyze how they affect replacement-purchase buying decisions. Second, we use data vis-à-vis components or contents as a proxy for convergence mobile phone sales data. Finally, based on [7], we model the diffusion of the related single-function products, with the assumption that the introduction of a convergence mobile phone might have an effect on the diffusion of that product.

\section{Model}

The convergence phone is, in terms of functionality, both a mobile phone and another product, such as a digital camera or an MP3 player. Therefore, in terms of the marketplace, the convergence phone is located at the intersection of the mobile phone market and another product's market as depicted in Fig. 4.

The replacement-purchase diffusion model is used to analyze the respective diffusion patterns of mobile phones, and the multiproduct diffusion model is used to analyze the substitutive or complementary relationships between the convergence phone and its related single-function products. Henceforth, we will consider the case of camera phones as case I, and that of MP3 mobile phones as case II.

\section{Diffusion Model for Mobile Phones}

Consumer demand in the mobile phone market can be divided into first purchases and replacement purchases. The

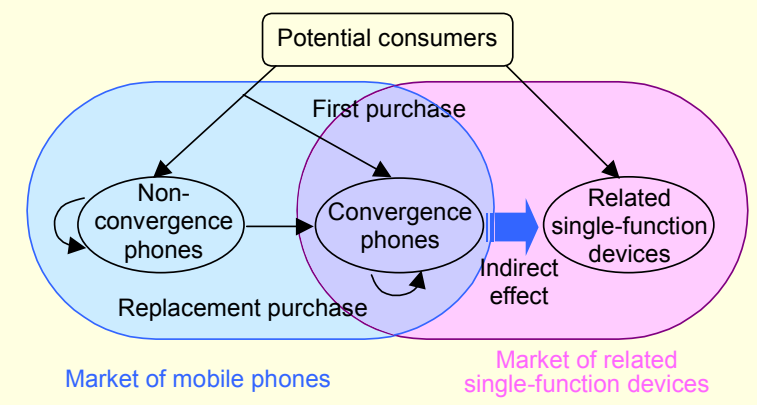

Fig. 4. Markets of convergence phones and their related singlefunction devices.

first purchase is the purchase of a product by a consumer who has not previously purchased the product. First purchases of mobile phones are represented as the number of new subscribers to mobile telecommunications services, and new subscribers choose between convergence phones and nonconvergence phones. Replacement purchases are made by consumers who have already purchased mobile phones and are looking to buy new mobile phones as replacements. They can either change their type of mobile phones or stay with their existing phone types. In other words, a user of a nonconvergence phone can replace it either with the same type or with a convergence phone, and a user of a convergence phone can also replace it with the same type or with a nonconvergence phone. We ignore the scenario of replacing a convergence phone with a non-convergence phone because we assume that technological retrogression is an unusual occurrence in the actual market.

Sales of mobile phones at time $t$ are then represented as

$$
x_{i}(t)=s_{i}(t)+r_{i}(t), \quad i=1,2,
$$

where subscripts 1 and 2 represent the non-convergence phone and convergence phone, respectively, and $s_{i}(t)$ and $r_{i}(t)$ represent first purchases and replacement purchases, respectively.

We use a logistic model for new subscribers to mobile telecommunications services, ${ }^{2)}$ and we assume that a portion $\alpha$ of new subscribers choose the non-convergence phone and a portion $(1-\alpha)$ choose the convergence phone. Assuming that consumers who have a replacement cycle $T_{j}$ make replacement purchases in the portion of $\gamma_{i j}$, the replacement sales of mobile phones $i$ are arrived at by ${ }^{3)}$

$$
r_{i}(t)=\sum_{j=1}^{3} \gamma_{i j} x_{i}\left(t-T_{j}\right), \quad i=1,2 .
$$

2) Meade and Islam [24] suggest that the logistic model is appropriate to the diffusion of technologies that have a network effect, as is the case with telecommunication services.

3) Lee and Lee [17] assume three replacement cycles: one, two, and more than three years. This assumption is based on survey results of [25] indicating that the replacement cycle of Koreans' mobile phones is between one and two years. 
We assume that a portion $\beta(t)$ of users of the nonconvergence phone will opt for a convergence phone at replacement time. We also assume that some variables can affect the replacement of a non-convergence phone with a convergence phone. Thus, sales of each mobile phone at time $t$ are modeled as

$$
\begin{aligned}
x_{1}(t)= & \alpha \frac{d S(t)}{d t}+\{1-\beta(t)\} \times \sum_{j=1}^{3} \gamma_{1 j} x_{1}\left(t-T_{j}\right), \\
x_{2}(t)= & (1-\alpha) \frac{d S(t)}{d t}+\sum_{j=1}^{3} \gamma_{2 j} x_{2}\left(t-T_{j}\right) \\
& +\beta(t) \sum_{j=1}^{3} \gamma_{1 j} x_{1}\left(t-T_{j}\right), \\
& \text { where } S(t)=\frac{m_{s}}{1+\exp (-a-b t)} .
\end{aligned}
$$

Here, $S(t)$ represents the cumulative number of subscribers to a mobile telecommunications service, parameter $m_{s}$ represents the potential cumulative number of subscribers, and parameters $a$ and $b$ represent the initial level and the growth rate of diffusion, respectively.

For case I, we consider the effects of variables, namely, the average pixel ratio of camera phones to digital cameras $(\operatorname{pixel}(t))$ and the number of camera phone models $\left(\right.$ nom $\left._{c}(t)\right)$ on the replacement-demand of non-camera phone owners for camera phones as given in (5-1). For case II, we consider the effects of variables, namely, average memory capacity of the MP3 mobile phone $(\operatorname{mem}(t))$, the number of models of MP3 mobile phones $\left(\operatorname{nom}_{m}(t)\right)$, and the average number of MP3 mobile phones with Bluetooth functionality $($ blue $(t))$ as given in (5-2).

$$
\begin{gathered}
\beta(t)=\beta_{1} \operatorname{pixel}(t)+\beta_{2} \text { nom }_{c}(t), \\
\beta(t)=\beta_{3} \operatorname{mem}(t)+\beta_{4} \text { nom }_{m}(t)+\beta_{5} \text { blue }(t) .
\end{gathered}
$$

We use data regarding components or contents as a proxy for convergence mobile phone sales data. In case I, the number of sales of camera phones is the same as that of sales of its component, the image sensor semiconductor. However, in case II, we must modify these equations because it is difficult to collect the exact market sales data for MP3 mobile phones. Users of MP3 mobile phones are inclined to join one of the three mobile telecommunications service providers' online music services: Melon, Dosirak, or Musicon. Therefore, we can use the number of members of the online music services as a proxy for MP3 mobile phone sales data. However, because data outlining the number of members of the online music services (or Internet sites) is also unavailable, we use the number of visitors to those Internet sites. The number of visitors to the online music sites may be different from the number of members who join and indeed use the services, but it may have a relationship with sales data for MP3 mobile phones. Therefore, we assume (6) to model the relationship between the number of online visitors and MP3 mobile phone sales. Parameter $k$ is estimated endogenously in our model:

$$
x_{2}(t)=k \cdot w e b(t),
$$

where $w e b(t)$ is the number of visitors to online music services at time $t$.

\section{Diffusion Model for Digital Cameras}

We considered both the logistic model and the Bass model to analyze the diffusion of digital cameras; however, we found that the logistic model shows better fitting in terms of the $\mathrm{R}$-squared value and the number of significant parameters, and this aligns with the findings of [24]. To analyze how camera phones affect the market potential of digital cameras, we consider a dummy variable $\left(d u m_{d c}\right)$, which is 0 before the introduction of the camera phone and 1 after the introduction of the camera phone. Equation (7) defines the cumulative sales of digital cameras:

$$
D C(t)=\frac{m_{d c}\left(1+\theta_{d c} \cdot d u m_{d c}\right)}{1+\exp \left(-p_{d c}-q_{d c} t\right)},
$$

where $D C(t)$ equals the cumulative sales of digital cameras at time $t$. The parameters $m_{d c}, p_{d c}$, and $q_{d c}$ represent market potential, initial level, and growth rate of diffusion, respectively.

\section{Diffusion Model for MP3 Players}

To analyze the diffusion of MP3 players, we again considered both the logistic model and the Bass model and found that the Bass model is a better fit in terms of the $\mathrm{R}$-squared value and the number of significant parameters. For this reason, the Bass model was used to represent the diffusion of MP3 players. In addition, according to the assumption that the introduction of the MP3 mobile phone will have an effect on the market potential of MP3 players, we also consider a dummy variable $\left(d_{m} m_{m p}\right)$, which is 0 before the introduction of the MP3 mobile phone and 1 after the introduction of the MP3 mobile phone. Sales of the MP3 player at time $t$ are represented as

$$
\begin{aligned}
m p(t)= & \left\{p_{m p}+q_{m p} \frac{M P(t-1)}{m_{m p}\left(1+\theta_{m p} \cdot d u m_{m p}\right)}\right\} \\
& \times\left\{m_{m p}\left(1+\theta_{m p} \cdot d u m_{m p}\right)-M P(t-1)\right\},
\end{aligned}
$$

where $m p(t)$ and $M P(t)$ represent the sales and the cumulative sales of MP3 players at time $t$, respectively. Parameters $m_{m p}$, $p_{m p}$, and $q_{m p}$ represent the market potential, the innovation 
coefficient, and the imitation coefficient of the Bass model, respectively.

\section{Empirical Analysis}

\section{Data}

Data regarding the number of subscribers to mobile telecommunications services is available from the IT statistics of Korea. ${ }^{4}$ Sales data for mobile phones, digital cameras, and MP3 players is available from the Korea National Statistical Office. ${ }^{5)}$ To estimate the model, we collected data on the South Korean mobile phone and MP3 player markets covering the 72-month period from January 2001 to December 2006.

However, we could not acquire sales data for camera phones; therefore, as a proxy, we used sales data for an important component of the camera phone, namely, the image sensor semiconductor. In addition, because MP3 mobile phone sales data is also unavailable, we obtained the number of visitors to the online music sites (Melon, Dosirak, and Musicon) from Metrix, a South Korean market research institute. As previously mentioned, this approach may be reasonable in that the camera phone and MP3 mobile phone have a one-to-one relationship with their components or online service, respectively.

Data on some attributes of convergence phones was collected through the South Korean mobile review site, Cetizen.com, and several South Korean price comparison web sites. ${ }^{\text {) }}$ The data includes the average pixel ratio of camera phones to digital cameras, the number of camera phone models, average memory capacity of MP3 mobile phones, the number of MP3 mobile phone models, and the average number of Bluetooth-enabled MP3 mobile phones.

\section{Case I: Mobile Phones and Digital Cameras}

For case I, we need to estimate (3), (4), (5-1), and (7). However, in (3) and (4), the least squares estimators are inconsistent because the endogenous variables are correlated with the error terms. Therefore, we estimate the parameters of (3) and (4) simultaneously using three-stage least squares (3SLS) as proposed in [26]. In contrast, the model for the digital camera, (7), is estimated using nonlinear least squares (NLS) and all estimations were conducted using TSP software, version 4.5. The estimation results are presented in Table 1.

For the model of subscribers to mobile telecommunications services, all parameters are statistically significant and have the

\footnotetext{
4) http://www.itstat.go.kr/

5) http://stat.nca.or.kr/

6) www.danawa.com, www.omi.co.kr, and www.enuri.com
}

Table 1. Estimation results: case I.

\begin{tabular}{|c|c|r|r|r|}
\hline \multirow{2}{*}{ Parameter } & \multicolumn{2}{|c|}{ Mobile phone } & \multicolumn{2}{c|}{ Digital camera } \\
\hline & Coefficient & $t$-statistic & Coefficient & $t$-statistic \\
\hline$m_{s}$ & $45,110,710^{*}$ & 29.01 & & \\
\hline$a$ & $-2.7277^{*}$ & -10.46 & & \\
\hline$b$ & $0.0234^{*}$ & 9.50 & & \\
\hline$\alpha$ & $0.9351^{*}$ & 7.32 & & \\
\hline$\beta_{1}$ & $2.9847^{*}$ & 2.89 & & \\
\hline$\beta_{2}$ & 0.0006 & 0.35 & & \\
\hline$\gamma_{11}$ & $0.0507^{*}$ & 3.85 & & \\
\hline$\gamma_{12}$ & 0.0229 & 1.71 & & \\
\hline$\gamma_{13}$ & 0.0011 & 0.07 & & \\
\hline$\gamma_{21}$ & $0.0820^{*}$ & 6.62 & & \\
\hline$\gamma_{22}$ & $-0.0966^{*}$ & -3.76 & & \\
\hline$\gamma_{23}$ & $0.1381^{*}$ & 6.77 & & \\
\hline$m_{d c}$ & & & $2,484,628^{*}$ & 15.63 \\
\hline$\theta_{d c}$ & & & $-0.1504^{*}$ & -4.55 \\
\hline$p_{d c}$ & & & $-1.8490^{*}$ & -20.62 \\
\hline$q_{d c}$ & & & $0.0480^{*}$ & 15.73 \\
\hline $\mathrm{R}-\mathrm{squared}$ & \multicolumn{2}{|c|}{0.9310} & & 0.9697 \\
\hline
\end{tabular}

*: Statistically significant at $1 \%$

expected signs, indicating that this logistic model is appropriate for explaining the diffusion of mobile telecommunications service subscribers. Also, most parameters (except $\beta_{2}, \gamma_{12}$, and $\gamma_{13}$ ) have the expected signs and statistically significant coefficients. In particular, the coefficient of $\beta_{1}$ is strongly positive, so we can expect that the average pixel ratio of camera phones to digital cameras promotes the replacement of non-camera phones with camera phones. In other words, the more advanced the camera functions of camera phones become, the more likely it is that consumers will want to purchase camera phones rather than non-camera phones. However, $\beta_{2}$ is not statistically significant, meaning that the number of camera phone models does not affect the number of replacement purchases from non-camera phones to camera phones.

From the results, we calculated the average replacement cycle. On average, consumers who purchased a non-camera phone tended to change their mobile phone to a camera phone after 17.4 months. However, consumers who purchased a camera phone tended to purchase another camera phone every 16.6 months. In addition, the replacement sales of camera phones are three times larger than those of non-camera phones. It can therefore be said that replacement purchases of camera phones occur more frequently than those of non-camera 


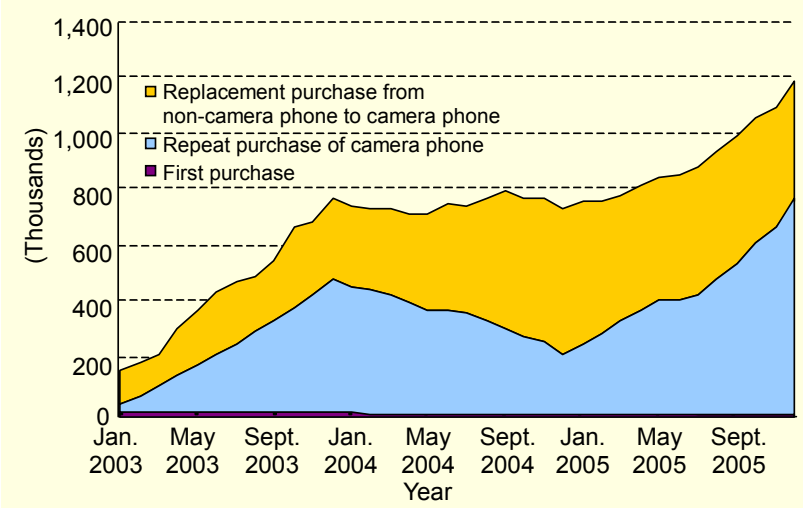

Fig. 5. Estimated sales of camera phones.

phones, and that the total sales of mobile phones increase as a result of sales of camera phones. This phenomenon is explained by the fact that consumers put more importance on a mobile phone's additional functions than on its basic functions, and that a consumer's desire to change his or her mobile phone increases as additional functions are improved.

On the other hand, in the results of the digital camera model, $\theta_{d c}$ has a negative coefficient, so we can expect the diffusion of camera phones to have a negative effect on that of digital cameras. In addition, the market potential of the digital camera has been decreased by about $15 \%$ due to the introduction of the camera phone. This phenomenon will intensify as the functions of camera phones improve and as more consumers purchase camera phones.

Figure 5 shows the estimated sales for camera phones including first purchases, replacement purchases from noncamera phones to camera phones, and repeat purchases. Most sales of camera phones are replacement purchases, and first purchases of camera phone make up only about $1 \%$ of total sales. Moreover, the proportion of replacement purchases of camera phones can be expected to increase as the demand for non-camera phones decreases.

\section{Case II: Mobile Phones and MP3 Players}

For case II, (3) and (4) are modified for estimation purposes using (6) and the condition $x_{1}(t)=x(t)-x_{2}(t)$, where $x(t)$ represents the total sales of mobile phones. For convenience, we assume that $\gamma_{i j}=\gamma_{j}$. Equations (3), (4), (5-2), and (8) are estimated using 3SLS and NLS with TSP in the same manner as that used for case I. The results are presented in Table 2.

From the results, parameter $\alpha$ is statistically significant and nearly has a value of 1 , meaning that most of the new mobile telecommunications service subscribers choose non-MP3 mobile phones. However, because the first-purchase market has already matured, the portion of total sales represented by
Table 2. Estimation results: case II.

\begin{tabular}{|c|c|c|c|c|}
\hline \multirow{2}{*}{ Parameter } & \multicolumn{2}{|c|}{ Mobile phone } & \multicolumn{2}{|c|}{ MP3 player } \\
\hline & Coefficient & $t$-statistic & Coefficient & $t$-statistic \\
\hline$m_{s}$ & $45,943,280^{*}$ & 59.38 & & \\
\hline$a$ & $-2.6573^{*}$ & -21.88 & & \\
\hline$b$ & $0.0225^{*}$ & 19.59 & & \\
\hline$\alpha$ & $1.0098^{*}$ & 17.80 & & \\
\hline$k$ & $0.1997^{*}$ & 8.35 & & \\
\hline$\beta_{3}$ & $0.0014^{* *}$ & 2.10 & & \\
\hline$\beta_{4}$ & -0.0021 & -1.47 & & \\
\hline$\beta_{s}$ & $14.8898^{*}$ & 3.78 & & \\
\hline$\gamma_{1}$ & $0.0486^{*}$ & 5.31 & & \\
\hline$\gamma_{2}$ & 0.0093 & 1.21 & & \\
\hline$\gamma_{3}$ & 0.0147 & 1.91 & & \\
\hline$m_{m p}$ & & & $3,044,185^{*}$ & 12.67 \\
\hline$\theta_{m p}$ & & & $0.1513^{*}$ & 2.17 \\
\hline$p_{m p}$ & & & 0.0030 & 1.81 \\
\hline$q_{n p}$ & & & $0.0641^{*}$ & 7.17 \\
\hline R-squared & \multicolumn{2}{|c|}{0.9674} & \multicolumn{2}{|c|}{0.4761} \\
\hline
\end{tabular}

first purchases may be small. Within the replacement-purchase segment, $\gamma_{1}$ is statistically significant and positive, so it can be said that about $5 \%$ of consumers who have a replacement cycle of one year make a replacement purchase every month.

The results of $\beta_{3}, \beta_{4}$, and $\beta_{5}$ show the effects of attributes related to MP3 mobile phones on replacement purchases by consumers who previously owned non-MP3 mobile phones. First, $\beta_{3}$, which represents the effect of the MP3 mobile phone's memory capacity, is statistically significant and positive. This signifies that the MP3 mobile phone may assume the role of a music player with improvements to memory capacity. When that occurs, consumer demand for MP3 mobile phones increases. Second, $\beta_{4}$ is not statistically significant; thus, we can infer that the number of models of MP3 mobile phones introduced to the market does not have an effect on purchases of MP3 mobile phones. In fact, the actual global market supports this result. Over the past two years, Motorola has achieved a $10 \%$ profit margin through sales of a single product model, the RAZR, and Sony Ericsson has achieved about a $15 \%$ profit margin through the market success of its Walkman phone and its Cybershot phone series. Thus, to achieve success in the mobile phone market, a strategy concentrating on having a single "mega-hit" model is more important than a strategy of developing a number of product models. Finally, $\beta_{5}$ has a significant and positive estimator, meaning that making an 


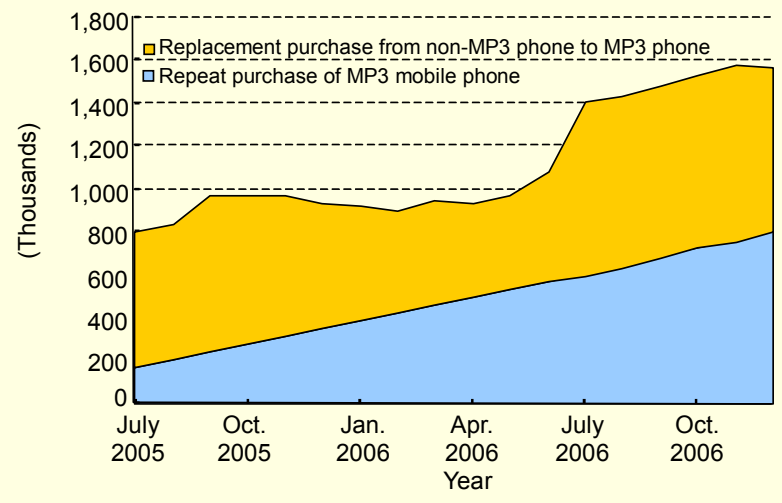

Fig. 6. Estimated sales of MP3 mobile phones.

MP3 mobile phone Bluetooth-ready has a positive effect on replacement purchases of MP3 mobile phones. The Bluetooth specification enables consumers to use their MP3 mobile phones more conveniently during phone calls or when listening to music. Therefore, improving MP3 mobile phones with attributes such as Bluetooth functionality means they may be used more as music-playing devices.

On the other hand, $k$, which represents the relationship between MP3 mobile phone sales and the number of visitors to online music sites, is statistically significant and estimated to be about 0.2 . In other words, each month, the number of visitors to the online music sites is five times larger than the number of MP3 mobile phones sold. This coefficient includes various effects such as the relationship between MP3 mobile phone sales and the number of legal users of online music services, the relationship between the number of legal users and the number of visitors, and the effect of visitors who do not join the site. Therefore, it is difficult to explain precisely the relationship between MP3 mobile phone sales and online membership to a content-providing service. However, this finding has the implication that when market sales data is unavailable, data from a content-providing service or a related service can be used in an empirical diffusion analysis. In any case, more detailed data is needed to analyze the exact relationship between mobile phone diffusion and content-providing services.

In the estimation results for MP3 players, most parameters are statistically significant. In particular, $\theta_{m p}$, which represents the effect of the introduction of MP3 mobile phones on the market potential for MP3 players, is positive. This means that the market size of diffusion of MP3 players is promoted by the introduction of MP3 mobile phones. These results indicate that consumers who become familiar with portable music-playing devices and MP3 files through the use of an MP3 mobile phone are more inclined to seek out and adopt more advanced and specialized music players than mobile phones. Therefore, it can be concluded that convergence mobile phones, which include some other digital devices' function(s), do substitute or play a complementary role in the diffusion of their related single-function product by virtue of their characteristics.

Figure 6 shows the estimated sales segments of the MP3 mobile phone: replacement purchases from non-MP3 mobile phones to MP3 mobile phones and replacement purchases of MP3 mobile phones. Based on these results, replacement purchases from non-MP3 mobile phones to MP3 mobile phones make up about 50 percent of total sales, and this proportion is likely to decrease because of the decreasing demand for nonMP3 mobile phones. The proportion of replacement purchases of MP3 mobile phones can also be expected to increase.

\section{Managerial Implications}

Camera phones with the external shape of a mobile phone and camera functions like those of a digital camera have a complementary relationship with mobile phones and a substitutive relationship with digital cameras. Our findings suggest that camera phone providers and related intermediate goods providers should consider business strategies such as giving the product a more compact size and advanced camera functions as well as compatibility with new services. Digital camera providers should pursue a strategy to differentiate their products from camera phones, which could include producing higher-performance images, increasing capacity, and making picture-taking more convenient.

In our findings, the results for MP3 mobile phones were the opposite of those for camera phones. In the case of MP3 mobile phones, a new convergence product can have a synergetic effect on the diffusion of its related single-function products and related markets. This result can be explained by the fact that MP3 mobile phones and MP3 players share a common feature. That is, they require MP3 or audio files, unlike the camera phones or digital cameras. In other words, consumers who use MP3 mobile phones necessarily become familiar with portable music players and MP3 files, and so consumer demand for MP3 players is increased by the diffusion of MP3 mobile phones and the proliferation of online music services. These results might resemble those of other music-playing devices such as portable media players. The continued diffusion of MP3 players can be ensured if, most importantly, consumers have access to music-file sources and if strategies focus on consumer convenience by, for example, increasing the compatibility of players with other multimedia devices.

Mobile phones that are products of convergence, such as camera phones, MP3 mobile phones, and mobile TV phones, lead the advanced mobile phone market in terms of replacement purchases, and their share of the replacement 
market is expanding. However, functions such as picture taking and music playing are gradually becoming basic functions of mobile phones. To compete for an advantage in the market, camera phone providers should consider additional telecommunications-related services. For example, given the development of mobile services such as WiMAX, ${ }^{7)}$ HSDPA, ${ }^{8)}$ and so on, the camera function can create added value in the area of image transmission: image printing, blog uploading, and so on. Also, MP3 mobile phone providers should consider strategies such as developing long-lasting batteries, increasing memory capacity, concentrating on ever lighter and slimmer designs, and improving movie and audio file-playing functions. In addition, mobile telecommunications service providers can create continuous consumer demand for MP3 mobile phones by providing mobile services and digital content, such as digital music and broadcasting.

\section{Conclusion}

This study presented a diffusion model to investigate the relationship between a convergence product and its related single-function products based on the concept of a replacement-purchase and multiproduct diffusion model. We empirically analyzed the diffusion pattern of the convergence mobile phone market in South Korea. In doing so, we found relationships between these convergence products and their related single-function products, the digital camera and the MP3 player.

To perform an empirical analysis, we employed replacement-purchase diffusion models and combined the effects of the salient attributes of convergence products on the replacement demand for mobile phones. The estimation results show that, in the South Korean mobile phone market, the rate of replacement purchases for convergence mobile phones is increasing continuously. Furthermore, that rate might accelerate if the attributes of the converged functions were further improved. Our research also demonstrates that camera phones can be substitutes for digital cameras, and that MP3 mobile phones have a complementary relationship with MP3 players.

We also found that to analyze the diffusion of a new convergence product, the diffusion of related markets should be considered concurrently because convergence products share characteristics with their related single-function products. Our approach can be applied to diffusion analysis of various convergence products and to the analysis of the effect of important convergence attributes by combining existing

7) World Interoperability for Microwave Access

8) High-Speed Downlink Packet Access diffusion models. Businesses and industries related to convergence products and telecommunications may also find this study's implications and information useful.

However, there are some limitations of this research. First, the model uses a binary variable, which could be rather simple and insufficient to address complex problems related to convergence products. If various terms such as the effect of sales or specific attributes of a convergence product on the diffusion of its related single-function products are included in empirical models, we can expect more fruitful and meaningful results. Second, the use of proxy variables such as component sales and related service subscriptions might not be entirely accurate. Acquisition of market sales data for the convergence product is necessary for an in-depth analysis. Finally, in this paper, the model and the empirical analysis are focused on the Korean mobile phone market and might be only the first research step for general cases. Our approach could have many applications in further research.

\section{References}

[1] Y. Kim, J.D. Lee, and D. Koh, "Effects of Consumer Preferences on the Convergence of Mobile Telecommunications Devices," Applied Economics, vol. 37, no. 7, 2005, pp. 817-826.

[2] Y. Lee and G.C. O'Connor, "The Impact of Communication Strategy on Launching New Products: The Moderating Role of Product Innovativeness," Journal of Product Innovation Management, vol. 20, no. 1, 2003, pp. 4-21.

[3] R.W. Veryzer, "The Roles of Marketing and Industrial Design in Discontinuous New Product Development," Journal of Product Innovation Management, vol. 22, no. 1, 2005, pp. 22-41.

[4] J. Lind, "Ubiquitous Convergence: Market Definitions Generated by Technological Change and the Industry Life Cycle," Proc. DRUID Academy Winter 2005 Conference, Skorping, Denmark, 2005.

[5] C. Chute and D. Linsalata, "Market Analysis: Worldwide Camera Phone and Videophone 2005-2009 Forecast," IDC, 2005, Available from http://www.idc.com.

[6] M.L. Katz, "Remarks on the Economic Implications of Convergence," Industrial and Corporate Change, vol. 5, no. 4, 1996, pp. 1079-1096.

[7] R.A. Peterson and V. Mahajan, "Multi-product Growth Models," J. Sheth (ed.), Research in Marketing, Greenwich: JAI Press, 1978, pp. 201-231.

[8] J.A. Norton and F.M. Bass, "A Diffusion Theory Model of Adoption and Substitution for Successive Generations of HighTechnology Products," Management Science, vol. 33, no. 9, 1987, pp. 1069-1086.

[9] V. Mahajan and E. Muller, "Timing, Diffusion, and Substitution of Successive Generation of Technological Innovations: The IBM 
Mainframe Case," Technological Forecasting and Social Change, vol. 51, no. 2, 1996, pp. 109-132.

[10] T. Islam and M. Meade, "The Diffusion of Successive Generations of a Technology: A More General Model," Technological Forecasting and Social Change, vol. 56, no. 1, 1997, pp. 49-60.

[11] F.M. Bass, "A New Product Growth Model for Consumer Durables," Management Science, vol. 15, no. 5, 1969, pp. 215227.

[12] V. Mahajan, E. Muller, and F.M. Bass, "New Product Diffusion Models in Marketing: A Review and Directions for Research," Journal of Marketing, vol. 54, no. 1, 1990, pp. 1-26.

[13] G.I. Lilien, A.G. Rao, and S. Kalish, "Bayesian Estimation and Control of Detailing Effort in a Repeat-Purchase Diffusion Environment," Management Science, vol. 27, no. 5, 1981, pp. 493-506.

[14] A.G. Rao and M. Yamada, "Forecasting with a Repeat-Purchase Diffusion Model," Management Science, vol. 34, no. 6, 1988, pp 734-752.

[15] M.H. Hahn et al., "Analysis of New Product Diffusion Using a Four-Segment Trial-Repeat Model," Marketing Science, vol. 13, no. 3, 1994, pp. 224-247.

[16] D.B. Jun et al., "Forecasting Telecommunication Service Subscribers in Substitutive and Competitive Environments," International Journal of Forecasting, vol. 18, no. 4, 2002, pp. 561-581.

[17] C.Y. Lee and J. Lee, "Diffusion of Mobile Terminal Market: A Model Considering Repeat-Purchase," Korea Telecommunications Policy Review, vol. 12, no. 4, 2005, pp. 179201 (in Korean).

[18] C.A. Depken and L.C. Simmons, "Social Construct and the Propensity for Software Piracy," Applied Economics Letters, vol. 11, no. 2, 2004, pp. 97-100.

[19] K. Domon and N. Yamazaki, "Unauthorized File-Sharing and the Pricing of Digital Content," Economics Letters, vol. 85, no. 2, 2004, pp. 179-184.

[20] M. Peitz and P. Waelbroeck, "Why the Music Industry May Gain from Free Downloading: The Role of Sampling," International Journal of Industrial Organization, vol. 24, no. 5, 2006, pp. 907913.

[21] A. Takeishi and K.J. Lee, "Mobile Music Business in Japan and Korea: Copyright Management Institutions as a Reverse Salient,' Journal of Strategic Information Systems, vol. 14, no. 3, 2005, pp. 291-306.

[22] M. Givon, V. Mahajan, and E. Muller, "Software Piracy: Estimation of Lost Sales and the Impact on Software Diffusion," Journal of Marketing, vol. 59, no. 1, 1995, pp. 29-37.

[23] A. Prasad and V. Mahajan, "How Many Pirates Should a Software Firm Tolerate? An Analysis of Piracy Protection on the Diffusion of Software," International Journal of Research in
Marketing, vol. 20, no. 4, 2003, pp. 337-353.

[24] N. Meade and T. Islam, "Forecasting with Growth Curve: An Empirical Comparison," International Journal of Forecasting, vol. 11, no. 2, 1995, pp. 199-215.

[25] Cetizen, "Survey on Mobile Terminal Usage and Replacement Cycle," 2005, Available from http://www.cetizen.com (in Korean).

[26] A. Zellner and H. Theil, "Three-Stage Least Squares: Simultaneous Estimation of Simultaneous Equations," Econometrica, vol. 30, no. 1, 1962, pp. 54-78.

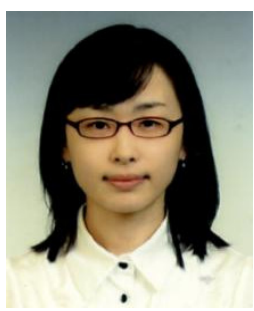

Misuk Lee received the BS degree in engineering from Seoul National University in 2003. Currently, she is a $\mathrm{PhD}$ candidate with the Technology Management, Economics, and Policy Program of Seoul National University. Her research interests include demand forecasting of new products/services, diffusion models for new technology, consumption efficiency, and high-tech marketing.

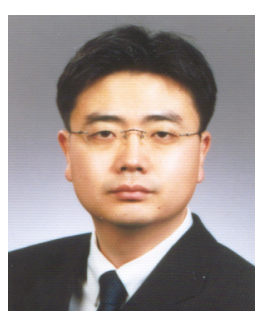

Jongsu Lee is an assistant professor of the Department of Industrial Engineering and Technology Management, Economics, and Policy Program of Seoul National University. His research interests include demand forecasting for new technologies/products/ services and related methodologies such as discrete choice models, diffusion models, and time series and panel data analysis.

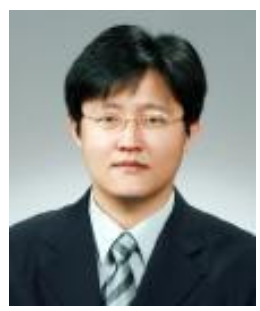

Youngsang Cho is a full-time lecturer of the School of Management of Inje University. He received his $\mathrm{PhD}$ degree from Seoul National University in 2007. His main research interests are diffusion of innovation, demand forecasting of high-tech products/services, NPD management, high-tech marketing, and technology convergence. 